\title{
Adaptabilidade e estabilidade em aveia em ambientes estratificados
}

\author{
Adaptability and stability in oat in stratified environments
}

\section{Giovani Benin $^{1}$ Fernando Irajá Félix de Carvalho ${ }^{2}$ Antônio Costa Oliveira ${ }^{2}$ Claudir Lorencetti $^{1}$ Eduardo Alano Vieira ${ }^{1}$ Jefferson Luís Meireles Coimbra ${ }^{1}$ Igor Pires Valério $^{3}$ Elmar Luíz Floss $^{4}$ Ivandro Bertan ${ }^{1}$ Giovani Olegário da Silva ${ }^{1}$}

\section{RESUMO}

\begin{abstract}
Vinte cultivares de aveia (Avena sativa L.) foram avaliados para rendimento de grãos nas safras agrícolas de 2001 e 2002 em nove locais dos estados do Paraná, Rio Grande do Sul e São Paulo, com o objetivo de avaliar as estimativas dos componentes de adaptabilidade e estabilidade do rendimento de grãos em ambientes favoráveis e desfavoráveis em presença e ausência de aplicação de fungicida. Foi empregada a metodologia de EBERHART \& RUSSELL (1966). A presença de significância para anos, genótipos, fungicidas e locais, indicou comportamento diferencial de genótipos frente às variações de ambiente e a aplicação de fungicida, nas condições de ambientes favoráveis e desfavoráveis. A aplicação de fungicida e o favorecimento do ambiente de cultivo afetaram intensamente os parâmetros de adaptabilidade $\left(b_{l}\right)$ e estabilidade $\left(\hat{\sigma}_{\delta \mathrm{i}}^{2}\right)$, indicando que estas estimativas devam ser realizadas em ambientes estratificados, apesar de nenhuma constituição genética ter evidenciado o biótipo ideal, conforme preconizado pelo modelo adotado.
\end{abstract}

Palavras-chave: interação genótipos $x$ ambientes; regressão linear simples; responsividade.

\section{ABSTRACT}

Twenty oat genotypes (Avena sativa L.) were evaluated for grain yield in the crop year of 2001 and 2002 in nine different locations in Paraná, Rio Grande do Sul and São Paulo states, Brazil. The objectives of this work were to obtain adaptability and stability parameters estimates in favorable and unfavorable environments with and without fungicide application. The methodology of EBERHART \& RUSSELL (1966) was applied.
The significance for years, genotypes, fungicides and locals indicated a differential behavior of genotypes in favorable and unfavorable environments with and without fungicide application. Data analysis shows that fungicide application and the favorable and unfavorable environment affected intensely the parameters of adaptability $\left(b_{l}\right)$ and stability $\left(\hat{\sigma}_{\delta \mathrm{i}}^{2}\right)$, indicating that these estimates must be performed in stratified environmental conditions, despite the fact that no ideal biotype was found, as predicted by the adopted model.

Key words: genotype $x$ environment interaction; linear regression; responsiveness.

\section{INTRODUÇÃO}

A aveia (Avena sativa L.) possui uma ampla área de cultivo dentro do território brasileiro, sendo uma espécie cujo desempenho é altamente influenciado pelas condições de ambiente, o que resulta em produtividade média instável ao longo dos anos. As grandes oscilações observadas nos níveis de produtividade são reflexos, principalmente, da sensibilidade dos genótipos às variações de ambiente.

Estudos com a cultura da aveia possibilitaram identificar respostas diferenciadas de genótipos a efeitos de ambiente (HOLLAND et al., 2000) e a presença de interação entre genótipos e ambientes, mesmo em ambientes estratificados

${ }^{1}$ Engenheiro Agrônomo, Doutor, Pós-doutorando em Agronomia (Setor de Genômica e Fitomelhoramento) na Universidade Federal de Pelotas (UFPel), Bolsista do Conselho Nacional de Desenvolvimento Científico e Tecnológico (CNPq). E-mail: giovbn@pop.com.br ${ }^{2}$ Engenheiro Agrônomo, PhD, Professor do Departamento de Fitotecnia, Faculdade de Agronomia Eliseu Maciel (FAEM) UFPel, Campus Universitário, CP 354, 96001-970, Pelotas, RS.

${ }^{3}$ Estudante do Curso de Agronomia, UFPel.

${ }^{4}$ Engenheiro Agrônomo, Doutor, Professor da Universidade de Passo Fundo (UPF). E-mail: floss @ upf.tche.br 
(BENIN et al., 2003). Além da diferença de ambientes (locais), a ferrugem da folha exerce forte influência no desempenho dos genótipos de aveia, podendo provocar perdas superiores a $50 \%$ de rendimento de grãos, principalmente em ambientes desfavoráveis (BENIN et al., 2003), aumentando, desta forma, a magnitude da interação entre as constituições genéticas e o ambiente. Além disso, LORENCETTI et al. (2004) observaram que a aplicação de fungicida afetou intensamente os parâmetros de adaptabilidade $\left(b_{1}\right)$, responsividade $\left(b_{1}+b_{2}\right)$ e estabilidade $\left(\hat{\sigma}_{\delta i}^{2}\right)$ de um conjunto de genótipos avaliados em treze ambientes (locais) de cultivo, indicando que as estimativas devam ser realizadas em ambientes com e sem fungicida individualizados.

Todos os métodos que visam caracterizar a adaptabilidade e estabilidade fenotípica fundamentam-se nas interações entre genótipos e ambientes. O mais antigo deles consiste em uma análise da variância conjunta de um experimento conduzido em vários locais numa sucessão de anos. Desta forma, pode ser determinado não somente os efeitos principais atribuíveis a cultivares, locais e anos, mas também as magnitudes das interações cultivar $\mathrm{x}$ local, cultivar $\mathrm{x}$ ano e cultivar $\mathrm{x}$ local $\mathrm{x}$ ano (OLIVEIRA, 1976). O método de EBERHART \& RUSSELL (1966), baseado na análise de regressão linear simples, tem sido um dos mais usados. A metodologia de EBERHART \& RUSSELL (1966) leva em consideração a variância do desvio da regressão como um parâmetro de estabilidade adicional. Esta metodologia conceitua como genótipo desejável aquele que apresenta rendimento médio alto, coeficiente de regressão igual à unidade e pequeno desvio da regressão.

O objetivo deste trabalho foi estudar a adaptabilidade $\left(\mathrm{b}_{1}\right)$ e estabilidade $\left(\hat{\sigma}_{\delta \mathrm{i}}^{2}\right)$ de um conjunto de vinte genótipos de aveia, em relação ao caráter rendimento de grãos, com avaliação em ambientes estratificados (favoráveis e desfavoráveis) na presença e ausência da aplicação de fungicida.

\section{MATERIAL E MÉTODOS}

Os dados experimentais relativos ao caráter rendimento de grãos $\left(\mathrm{kg} \mathrm{ha}^{-1}\right)$ foram provenientes do Ensaio Brasileiro de Cultivares Recomendadas de Aveia (EBCRA), coordenado pela Comissão Brasileira de Pesquisa de Aveia (CBPA). Os ensaios foram conduzidos na safra agrícola de 2001 e 2002 nos estados do Paraná, Rio Grande do Sul e São Paulo, totalizando nove locais distintos (Tabela 1).

Todos os ensaios foram instalados em delineamento experimental de blocos completos casualizados com seis repetições por tratamento (três com a aplicação de fungicida e três sem). De acordo com a necessidade de cada ambiente, foi efetuada de uma a duas aplicações do fungicida Tebuconazole (Folicur), na dose de 0,75 litros/ha do produto comercial. O rendimento de grãos foi transformado em $\mathrm{kg} \mathrm{ha}^{-1}$ a partir da área útil das parcelas que, conforme o ambiente, variaram de 3,0 a $4,25 \mathrm{~m}^{2}$. O espaçamento entre linhas foi de 0,20 metros e a densidade de semeadura de 250 sementes viáveis por metro linear. As adubações de semeadura e cobertura foram realizadas de acordo com a análise de solo de cada local, sendo os tratos culturais efetuados quando necessários.

Os experimentos com e sem a aplicação de fungicida foram estratificados em ambientes favoráveis e desfavoráveis, ou seja, ambientes que apresentaram médias superiores ou inferiores à média da análise conjunta (Tabela 1). Os dados de rendimento de grãos foram submetidos à análise de

Tabela 1 - Classificação dos ambientes com base no local de instalação em presença e ausência de aplicação de fungicida. Pelotas, RS 2004.

\begin{tabular}{|c|c|c|c|c|c|}
\hline \multirow{2}{*}{$\mathrm{N}^{\mathrm{o}}$} & \multirow{2}{*}{ Local } & \multicolumn{2}{|c|}{ Com fungicida } & \multicolumn{2}{|c|}{ Sem fungicida } \\
\hline & & 2001 & 2002 & 2001 & 2002 \\
\hline 1 & Pelotas (RS) & Desfavorável & Desfavorável & Desfavorável & Desfavorável \\
\hline 2 & Mauá da Serra (PR) & Favorável & Favorável & Favorável & Favorável \\
\hline 3 & Londrina (PR) & Desfavorável & Favorável & Desfavorável & Favorável \\
\hline 4 & Eldorado do Sul (RS) & Desfavorável & Favorável & Desfavorável & Desfavorável \\
\hline 5 & Entre Rios (PR) & Favorável & Favorável & Favorável & Desfavorável \\
\hline 6 & São Carlos (SP) & Desfavorável & Favorável & Favorável & Favorável \\
\hline 7 & Vacaria (RS) & Favorável & Desfavorável & Favorável & Desfavorável \\
\hline 8 & Pato Branco (PR) & Desfavorável & Desfavorável & Favorável & Desfavorável \\
\hline 9 & Ponta Grossa (PR) & Favorável & Desfavorável & Favorável & Desfavorável \\
\hline
\end{tabular}

Ciência Rural, v.35, n.2, mar-abr, 2005. 
variância, considerando o efeito de genótipo fixo e o de ambiente aleatório, sendo realizadas cinco análises independentes: com fungicida em ambientes favoráveis, com fungicida em ambientes desfavoráveis, sem fungicida em ambientes favoráveis, sem fungicida em ambientes desfavoráveis e a análise conjunta, que incluiu todos os ambientes estudados. A média do rendimento de grãos foi comparada pelo teste de Scott e Knott em nível de 5\% de probabilidade de erro. Os parâmetros de adaptabilidade e estabilidade foram estimados pela metodologia de EBERHART \& RUSSELL (1966), baseado na regressão linear simples, utilizando o programa computacional Genes (CRUZ, 2001). A dissimilaridade entre ambientes favoráveis e desfavoráveis foi quantificada através do Quadrado da Distância Euclidiana Média (CRUZ \& REGAZZI, 1997), e do método de agrupamento UPGMA, utilizando o programa computacional NTSYS (ROHLF, 2000).

\section{RESULTADOS E DISCUSSÃO}

A classificação dos locais quanto ao favorecimento do ambiente, nas situações com e sem a aplicação de fungicida, consta na tabela 1. Os municípios de Pelotas (RS) e Mauá da Serra (PR), independente do ano e da aplicação de fungicida, sempre apresentaram comportamento desfavorável e favorável, respectivamente. Para os demais locais, a classificação do favorecimento dos ambientes foi dependente do ano e da aplicação de fungicida. $\mathrm{O}$ efeito de ano pode ser claramente observado no município de Londrina (PR), sendo este desfavorável nas condições com e sem a aplicação de fungicida na safra agrícola de 2001 e favorável nestas mesmas condições na safra agrícola de 2002. Um grande número de locais, dentre eles, Eldorado do Sul (RS), Entre Rios (RS), São Carlos (SP), Pato Branco (PR) e Ponta Grossa (PR), modificaram seu comportamento de desfavorável para favorável após a aplicação de fungicida, justificando o uso de fungicida em locais responsivos e propícios à ocorrência da ferrugem da folha.

Os valores de quadrados médios de tratamentos, resultantes da análise de variância em ambientes favoráveis e desfavoráveis com e sem a aplicação de fungicida estão inseridos na tabela 3. A análise conjunta revelou diferenças significativas para os efeitos principais anos (A), fungicidas (F), locais (L) e genótipos $(\mathrm{G})$ e para todas as interações. Nas análises por grupo de ambientes, o efeito principal de genótipos não foi significativo para ambientes favoráveis com a aplicação de fungicida; nesta condição, o controle da ferrugem da folha e a presença de condições ideais para a expressão do potencial genético não possibilitaram diferenciar o conjunto de genótipos para o caráter rendimento de grãos. A significância das interações indica a existência de diferenças de genótipos quanto a suas respostas às variações de ambiente $(\mathrm{G} \times \mathrm{L})$ e de ambientes à aplicação de fungicida (F x L). Também indica que o conjunto de genótipos respondeu de forma diferenciada à aplicação de fungicida $(\mathrm{G} \times \mathrm{F})$, estando de acordo com BENIN et al. (2003) e LORENCETTI et al. (2004).

A magnitude dos quadrados médios em ambientes favoráveis e desfavoráveis com e sem a aplicação de fungicida demonstrou a existência de uma ampla variação dentro e entre os quatro grupos de ambientes utilizados neste estudo. Nas análises dos ambientes estratificados com e sem fungicida, o efeito principal de local dos ambientes favoráveis e desfavoráveis apresentaram os maiores valores de quadrados médios (Tabela 2), revelando, desta forma, a grande importância de ser considerado o local no momento da recomendação dos cultivares de aveia, estando de acordo com FEDERIZZI et al. (1993), BENIN et al. (2003) e LORENCETTI et al. (2004), que apontaram grande contribuição de locais na modificação do comportamento dos genótipos estudados. Segundo ALLARD \& BRADSHAW (1964), ambientes distintos são imprescindíveis em um programa de melhoramento para a seleção, detecção e recomendação de genótipos mais responsivos e adaptados a condições específicas de cultivo. O elevado valor do quadrado médio de locais (L) é determinado possivelmente pela ampla extensão de áreas que envolvem os locais utilizados no Ensaio Brasileiro de Cultivares Recomendadas de Aveia (EBCRA), que vão desde São Paulo até Pelotas no extremo sul do Rio Grande do Sul. Os coeficientes de variação oscilaram de 11 a $25 \%$, conferindo boa precisão às estimativas preditas nestes experimentos. Entretanto, em ambientes desfavoráveis sem a aplicação de fungicida, a maior magnitude do coeficiente de variação demonstra maior necessidade de controle de técnicas experimentais (aumento do tamanho de parcela e do número de repetições), a fim de possibilitar maior confiabilidade dos resultados.

A grande diferença entre ambientes pode ser quantificada pela análise da figura 1 , na qual pode ser observado que as distâncias foram mais acentuadas quando um conjunto de genótipos foi avaliado na condição sem a aplicação de fungicida (Figura 1A). Nesta condição, os ambientes favoráveis e 
Tabela 2 - Fontes de variação e seus respectivos quadrados médios e significâncias do caráter rendimento de grãos, em kg ha ${ }^{-1}$, obtidos do EBCRA em 9 locais nas safras agrícolas de 2001 e 2002. Pelotas, RS - 2004.

\begin{tabular}{|c|c|c|c|c|c|c|}
\hline \multirow{4}{*}{ Fontes de variação } & \multicolumn{6}{|c|}{ Quadrados médios (QM) } \\
\hline & \multicolumn{2}{|c|}{ Análise conjunta } & \multicolumn{4}{|c|}{ Análises individuais } \\
\hline & \multirow{2}{*}{ GL } & \multirow{2}{*}{ QM } & \multicolumn{2}{|c|}{ Com fungicida } & \multicolumn{2}{|c|}{ Sem fungicida } \\
\hline & & & Favorável & Desfavorável & Favorável & Desfavorável \\
\hline Anos (A) & 1 & $295966168 *$ & - & - & - & - \\
\hline Fungicidas $(\mathrm{F})$ & 1 & $364493124 *$ & - & - & - & - \\
\hline Locais (L) & 8 & $132206985^{*}$ & $35386888.32 *$ & $28577913.94 *$ & $12902652,27 *$ & $7402209.80^{*}$ \\
\hline Genótipos (G) & 19 & $9867081 *$ & $1424173,57^{\mathrm{ns}}$ & $1907736.77 *$ & $4961634,58^{*}$ & $5767898.63 *$ \\
\hline Gx L & 152 & $152812^{*}$ & $650463.40 *$ & $626415.97 *$ & $1120387.33^{*}$ & $678839.39 *$ \\
\hline$A \times F$ & 1 & $89225813^{*}$ & - & - & - & - \\
\hline$A \times L$ & 8 & $734619 *$ & - & - & - & - \\
\hline $\mathrm{G} \times \mathrm{A}$ & 19 & 12993837* & - & - & - & - \\
\hline Fx L & 8 & $2611800^{*}$ & - & - & - & - \\
\hline Gx F & 19 & $1400295^{*}$ & - & - & - & - \\
\hline$A \times F \times L$ & 16 & $10062533 *$ & - & - & - & - \\
\hline $\mathrm{G} \times \mathrm{A} \times \mathrm{F}$ & 38 & $1412092 *$ & - & - & - & - \\
\hline C.V. & - & 21 & 11 & 15 & 14 & 25 \\
\hline
\end{tabular}

* Significativo a 5\% de probabilidade de erro pelo teste F.

${ }^{\text {ns }}$ Não significativo.

desfavoráveis foram reunidos em grupos distintos, devido à maior magnitude da interação entre as constituições genéticas e o ambiente. Da mesma forma, BENIN et al. (2003) e MARCHIORO et al. (2003) observaram que a aplicação de fungicida afetou intensamente os agrupamentos de genótipos formados. Entretanto, com a aplicação de fungicida (Figura 1B), alguns ambientes desfavoráveis passaram a responder de forma semelhante aos ambientes favoráveis, sendo reunidos nos mesmos grupos; isto ocorreu devido a alguns ambientes desfavoráveis apresentarem comportamento semelhante aos ambientes favoráveis, após a aplicação de fungicida; demonstrando a importância das doenças fúngicas (principalmente a ferrugem da folha), na expressão do caráter RG e, conseqüentemente, na classificação dos ambientes em favoráveis e desfavoráveis. Estes resultados são de fundamental importância, pois demonstram que o potencial de rendimento de grãos da aveia é consideravelmente maximizado à medida que melhoram as condições do ambiente de cultivo. Da mesma forma, FREY (1964) encontrou maior grau de expressão de diferenças genéticas e maiores valores de herdabilidade em ausência de estresses de ambiente.

Os rendimentos médios $\left(b_{0}\right)$ dos genótipos, os parâmetros de adaptabilidade $\left(b_{1}\right)$ e estabilidade $\left(\hat{\sigma}_{\delta \mathrm{i}}^{2}\right.$ ) das análises individuais são evidenciados nas tabelas 3 e 4 . Em ambientes favoráveis com a aplicação de fungicida, o efeito de genótipos não revelou significância (Tabela 3), não sendo possível, portanto, declarar diferenças entre médias, demonstrando a necessidade de desenvolvimento de genótipos mais responsivos a estas condições de ambiente e com maiores respostas à aplicação de fungicida. Com a aplicação de fungicida, os genótipos avaliados em ambientes favoráveis apresentaram rendimento médio de grãos de $3558 \mathrm{~kg} \mathrm{ha}^{-1}$, sendo $63 \%$ superiores em relação aos ambientes desfavoráveis, que apresentaram rendimento médio de $2173 \mathrm{~kg} \mathrm{ha}^{-1}$. Sem a aplicação de fungicida, os ambientes favoráveis produziram rendimento médio de $3027 \mathrm{~kg} \mathrm{ha}^{-1}$, sendo $183 \%$ superiores em relação aos ambientes desfavoráveis, com rendimento médio de $1065 \mathrm{~kg} \mathrm{ha}^{-1}$. Estes resultados concordam com BENIN et al. (2003), que observaram grande diferença de expressão do potencial genético da cultura da aveia entre ambientes favoráveis e desfavoráveis, principalmente em ausência de tratamento fúngico.

A significância da interação G x L para os ambientes favoráveis e desfavoráveis com e sem a aplicação de fungicida (Tabela 2), justifica a necessidade de se proceder à análise de adaptabilidade e estabilidade fenotípica nestas condições específicas. Pode ser observado nas tabelas 3 e 4 que a aplicação de fungicida e o favorecimento do ambiente exerceram forte influência sobre os parâmetros de adaptabilidade.

Ciência Rural, v.35, n.2, mar-abr, 2005. 
Tabela 3 - Médias gerais $\left(b_{0}\right)$, parâmetros de adaptabilidade $\left(b_{1}\right)$ e estabilidade $\left(\hat{\sigma}_{\delta \mathrm{i}}^{2}\right)$ do caráter rendimento de grãos, em kg ha ${ }^{-1}$, em ambientes favoráveis e desfavoráveis com a aplicação de fungicida, obtidos do EBCRA em 9 locais nas safras agrícolas de 2001 e 2002. Pelotas, RS - 2004.

\begin{tabular}{|c|c|c|c|c|c|c|c|c|c|c|}
\hline \multirow{2}{*}{ Genótipo } & \multicolumn{4}{|c|}{ Ambientes favoráveis } & \multirow[b]{2}{*}{$\mathrm{R}^{2}$} & \multicolumn{5}{|c|}{ Ambientes desfavoráveis } \\
\hline & $\mathrm{b}_{0}$ & & $\mathrm{~b}_{1}$ & $\hat{\sigma}_{\delta \mathrm{i}}^{2}$ & & $\mathrm{~b}_{0}$ & & $\mathrm{~b}_{1}$ & $\hat{\sigma}_{\delta \mathrm{i}}^{2}$ & $\mathrm{R}^{2}$ \\
\hline UPF 15 & $3455^{1}$ & a & $0,85^{\mathrm{ns}}$ & $195220 *$ & 82 & $1951^{1}$ & $\mathrm{~b}$ & $0,85^{\mathrm{ns}}$ & $64969 *$ & 89 \\
\hline UPF 16 & 3558 & $\mathrm{a}$ & $1,07^{\mathrm{ns}}$ & $407223^{*}$ & 65 & 2072 & $\mathrm{~b}$ & $0,89^{\mathrm{ns}}$ & $76531 *$ & 89 \\
\hline UPF 17 & 3340 & $\mathrm{a}$ & $1,33^{*}$ & $150650 *$ & 84 & 1872 & $\mathrm{~b}$ & $0,93^{\mathrm{ns}}$ & $347134 *$ & 71 \\
\hline UPF 18 & 3559 & $\mathrm{a}$ & $1,31^{*}$ & $240324 *$ & 81 & 2228 & $\mathrm{a}$ & $0,93^{\mathrm{ns}}$ & $166075^{*}$ & 83 \\
\hline UPF 19 & 3818 & $\mathrm{a}$ & $0,98^{\mathrm{ns}}$ & $135522 *$ & 85 & 2283 & $\mathrm{a}$ & $1,07^{\mathrm{ns}}$ & $169564 *$ & 83 \\
\hline UPFA 20 & 3738 & $\mathrm{a}$ & $1,04^{\mathrm{ns}}$ & $29342^{*}$ & 90 & 2513 & $\mathrm{a}$ & $1,19^{*}$ & $45934^{*}$ & 90 \\
\hline UFRGS 14 & 3635 & $\mathrm{a}$ & $0,77 *$ & $126742 *$ & 86 & 2417 & $\mathrm{a}$ & $1,29 *$ & $23367^{\mathrm{ns}}$ & 91 \\
\hline UFRGS 15 & 3275 & a & $0,77 *$ & $318150^{*}$ & 80 & 1730 & $\mathrm{~b}$ & $0,92^{\mathrm{ns}}$ & $136917 *$ & 84 \\
\hline UFRGS 16 & 3451 & $\mathrm{a}$ & $1,33^{*}$ & $254852 *$ & 80 & 2031 & $\mathrm{~b}$ & $1,09^{\mathrm{ns}}$ & 92944* & 87 \\
\hline UFRGS 17 & 3498 & $\mathrm{a}$ & $0,60 *$ & $187202 *$ & 82 & 2499 & $\mathrm{a}$ & $1,52 *$ & $61431^{*}$ & 90 \\
\hline UFRGS 18 & 3506 & $\mathrm{a}$ & $1,02^{\mathrm{ns}}$ & $140771^{*}$ & 84 & 1726 & $\mathrm{~b}$ & $0,92^{\mathrm{ns}}$ & $210715^{*}$ & 82 \\
\hline UFRGS 19 & 3498 & $\mathrm{a}$ & $0,88^{\mathrm{ns}}$ & $240640 *$ & 81 & 2006 & $\mathrm{~b}$ & $0,54^{*}$ & $87976^{*}$ & 87 \\
\hline URS 20 & 3351 & $\mathrm{a}$ & $1,00^{\mathrm{ns}}$ & $88521 *$ & 87 & 2028 & $\mathrm{~b}$ & $1,11^{\mathrm{ns}}$ & $95947 *$ & 87 \\
\hline URS 21 & 3497 & $\mathrm{a}$ & $0,78^{*}$ & $450850 *$ & 61 & 2521 & $\mathrm{a}$ & $0,72^{*}$ & $437705^{*}$ & 66 \\
\hline URS 22 & 3264 & $\mathrm{a}$ & $0,96^{\mathrm{ns}}$ & $228782^{*}$ & 82 & 2024 & $b$ & $0,42 *$ & $121743^{*}$ & 86 \\
\hline OR 2 & 3947 & $\mathrm{a}$ & $1,20^{*}$ & $223471^{*}$ & 82 & 2523 & $\mathrm{a}$ & $1,26^{*}$ & 91996* & 87 \\
\hline OR 3 & 3799 & $\mathrm{a}$ & $1,20^{*}$ & $188124^{*}$ & 82 & 2192 & $\mathrm{a}$ & $1,14^{\mathrm{ns}}$ & $78822^{*}$ & 89 \\
\hline OR 4 & 3922 & $\mathrm{a}$ & $1,12^{\mathrm{ns}}$ & $164631 *$ & 83 & 2300 & a & $1,17^{\mathrm{ns}}$ & $47172 *$ & 90 \\
\hline FAPA 4 & 3893 & $\mathrm{a}$ & $0,73^{*}$ & $143842 *$ & 84 & 2528 & $\mathrm{a}$ & $1,13^{\mathrm{ns}}$ & $149356^{*}$ & 84 \\
\hline$\underline{\mathrm{IAC}} 7$ & 3171 & $\mathrm{a}$ & $0,81^{\mathrm{ns}}$ & $159391 *$ & 84 & 2022 & $\mathrm{~b}$ & $0,81^{\mathrm{ns}}$ & $556208 *$ & 60 \\
\hline Médias & 3558 & - & - & - & - & 2173 & - & - & - & - \\
\hline C.V. & 11 & - & - & - & - & 15 & - & - & - & - \\
\hline
\end{tabular}

${ }^{1}$ Médias não seguidas de mesma letra diferiram significativamente entre si, pelo teste de Scott e Knott em nível de 5\% de probabilidade erro. $* 5 \%$ de probabilidade, pelo teste $\mathrm{t}$.

Em ambientes favoráveis com a aplicação de fungicida (Tabela 3), as estimativas de adaptabilidade $\left(b_{1}\right)$ variaram de 0,60 a 1,33; os cultivares UPF 17, UPF 18, OR 2 e OR 3 com valores de $b_{1}$ de 1,33, 1,31, 1,20 e 1,20 , respectivamente, maiores que 1,0 (significativos a 5\%), responderam à melhoria do ambiente; ainda com a aplicação de fungicida na condição de ambientes desfavoráveis, apenas o cultivar OR 2 demonstrou continuar respondendo à intensificação da qualidade do ambiente $(1,26)$, o que não foi observado para os cultivares UPF $17(0,93)$, UPF $18(0,93)$ e OR $3(1,14)$, que apresentaram comportamento de ampla adaptabilidade. Com a aplicação de fungicida, os cultivares UPF $15(0,85$ e 0,85), UPF 16 (1,07 e 0,89), UPF 19 (0,98 e 1,07), UFRGS 18 (1,02 e 0,92), URS 20 (1,00 e 1,11), URS $21(0,78$ e 0,72$)$, OR $4(1,12$ e 1,17$)$ e IAC $7(0,81$ e $0,81)$ mostraram o mesmo comportamento em ambientes favoráveis e adversos, respectivamente. Ainda na tabela 3 , pode ser observado que o $b_{1}$ dos cultivares UFRGS 14 e UFRGS 17 foi significativamente inferior à unidade $(0,77$ e 0,60 , respectivamente) em ambientes favoráveis e superior à unidade (1,29 e 1,52, respectivamente) em ambientes desfavoráveis, permitindo incremento no rendimento de grãos com a melhoria do ambiente na condição de ambientes desfavoráveis; isto demonstra que a adaptabilidade (responsividade) dos genótipos é altamente dependente das condições de ambiente. Também pode ser observado que os genótipos UPF 15, UPF 16, UPF 19, UFRGS 18, URS 20, URS 21, OR 2, OR 4 e IAC 7 não modificaram o comportamento de adaptabilidade com a modificação do favorecimento do ambiente (Tabela 3).

Em ambientes favoráveis sem a aplicação de fungicida (Tabela 4), as estimativas de adaptabilidade $\left(b_{1}\right)$ variaram de 0,24 a 1,64. Nesta condição, os cultivares URS 21 e OR 2 responderam à melhoria do ambiente, tanto na condição de ambientes favoráveis (1,38 e 1,40, respectivamente), quanto na condição de ambientes desfavoráveis $(1,57$ e 1,78, 


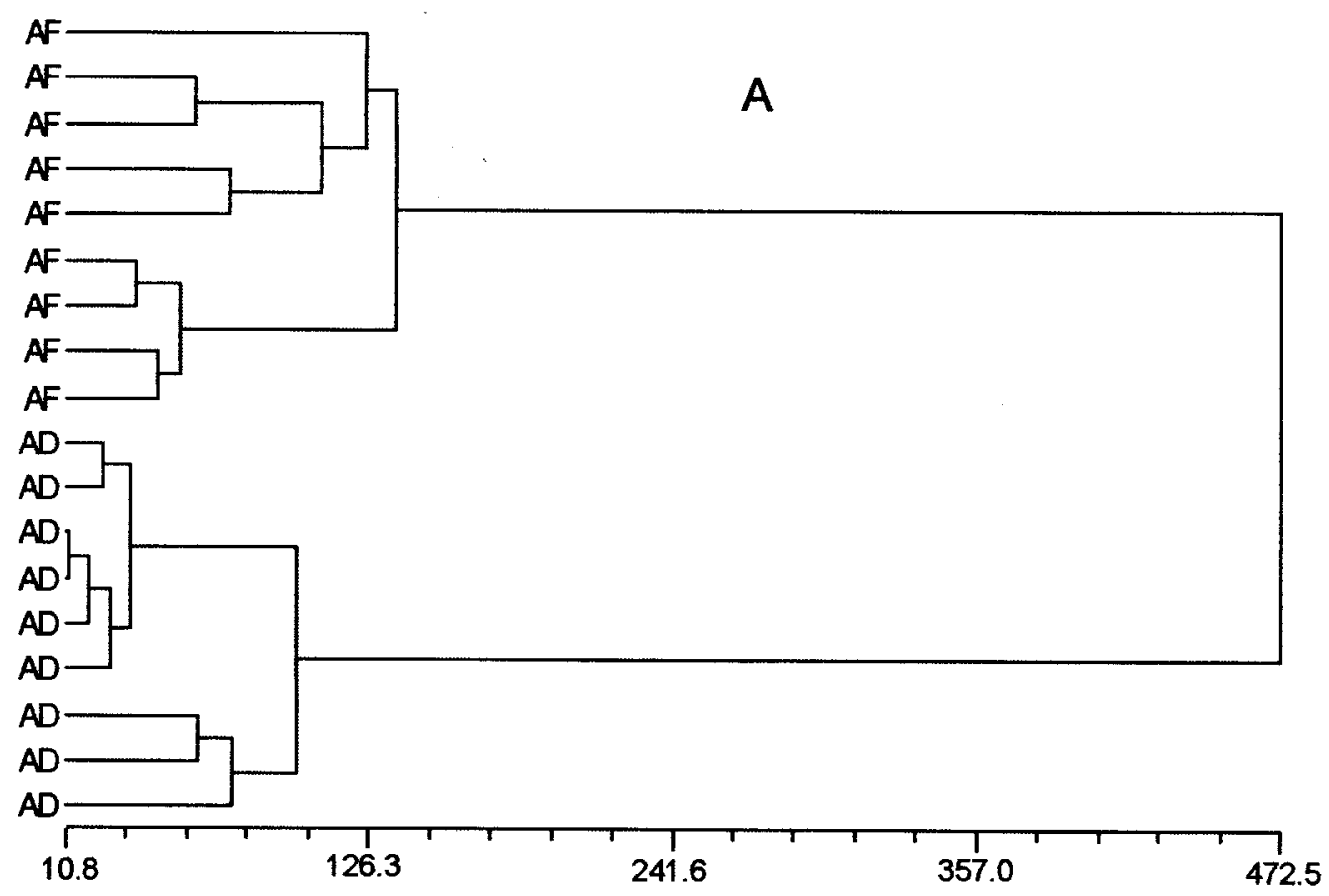

B

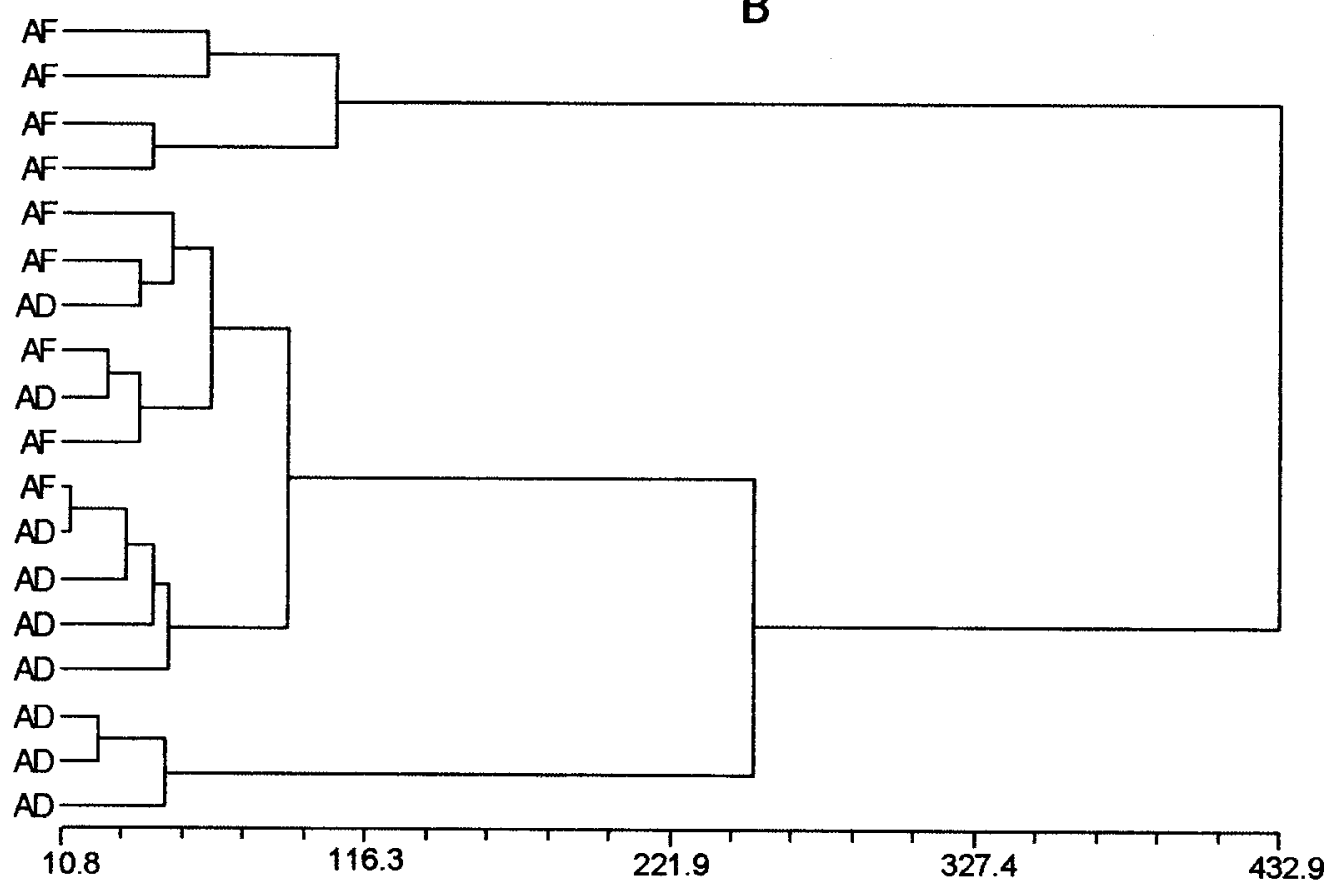

Figura 1 - Dissimilaridade genética entre ambientes favoráveis (AF) e ambientes desfavoráveis (AD) sem (A) e com (B) a aplicação de fungicida, quantificada através do Quadrado da Distância Euclidiana Média. Pelotas, RS - 2004.

Ciência Rural, v.35, n.2, mar-abr, 2005. 
Tabela 4 - Médias gerais (bo), parâmetros de adaptabilidade $\left(b_{1}\right)$ e estabilidade $\left(\hat{\sigma}_{\delta \mathrm{i}}^{2}\right)$ do caráter rendimento de grãos, em kg ha ${ }^{-1}$, em ambientes favoráveis e desfavoráveis sem a aplicação de fungicida, obtidos do EBCRA em 9 locais nas safras agrícolas de 2001 e 2002. Pelotas, RS - 2004.

\begin{tabular}{|c|c|c|c|c|c|c|c|c|c|c|}
\hline \multirow[b]{2}{*}{ Genótipo } & \multicolumn{4}{|c|}{ Ambientes favoráveis } & \multirow{2}{*}{$\mathrm{R}^{2}$} & \multicolumn{5}{|c|}{ Ambientes desfavoráveis } \\
\hline & $\mathrm{b}_{0}$ & & $\mathrm{~b}_{1}$ & $\hat{\sigma}_{\delta \mathrm{i}}^{2}$ & & $\mathrm{~b}_{0}$ & & $\mathrm{~b}_{1}$ & $\hat{\sigma}_{\delta \mathrm{i}}^{2}$ & $\mathrm{R}^{2}$ \\
\hline UPF 15 & $2702^{1}$ & $\mathrm{~b}$ & $0,53 *$ & $268604 *$ & 80 & $750^{1}$ & $\mathrm{~d}$ & $0,21 *$ & $64227^{*}$ & 89 \\
\hline UPF 16 & 2918 & $\mathrm{~b}$ & $1,32^{\mathrm{ns}}$ & $165721^{*}$ & 83 & 683 & d & $0,32 *$ & $125921^{*}$ & 86 \\
\hline UPF 17 & 2411 & $\mathrm{~b}$ & $0,73^{\mathrm{ns}}$ & $347155^{*}$ & 78 & 731 & $\mathrm{~d}$ & $0,27 *$ & $363461^{*}$ & 70 \\
\hline UPF 18 & 3298 & $\mathrm{a}$ & $1,17^{\mathrm{ns}}$ & $380244 *$ & 74 & 1499 & $\mathrm{~b}$ & $1,40^{*}$ & $291895^{*}$ & 80 \\
\hline UPF 19 & 2863 & $\mathrm{~b}$ & $0,24 *$ & $218618 *$ & 82 & 717 & $\mathrm{~d}$ & $0,41 *$ & $136572 *$ & 85 \\
\hline UPFA 20 & 3462 & $\mathrm{a}$ & $0,85^{\mathrm{ns}}$ & $56967^{\mathrm{ns}}$ & 90 & 1576 & $\mathrm{~b}$ & $1,46^{*}$ & $237830^{*}$ & 82 \\
\hline UFRGS 14 & 3141 & $\mathrm{a}$ & $0,81^{\mathrm{ns}}$ & $97053^{*}$ & 86 & 834 & $\mathrm{c}$ & $1,26^{\mathrm{ns}}$ & $157044^{*}$ & 84 \\
\hline UFRGS 15 & 2099 & $\mathrm{~b}$ & $0,53^{*}$ & $671682 *$ & 68 & 459 & $\mathrm{~d}$ & $-0,11^{*}$ & $84795^{*}$ & 89 \\
\hline UFRGS 16 & 3094 & $\mathrm{a}$ & $1,27^{\mathrm{ns}}$ & $181177^{*}$ & 83 & 1147 & $\mathrm{c}$ & $1,68^{*}$ & $18900^{\mathrm{ns}}$ & 94 \\
\hline UFRGS 17 & 2925 & $\mathrm{~b}$ & $0,94^{\mathrm{ns}}$ & $325090^{*}$ & 80 & 596 & d & $0,88^{\mathrm{ns}}$ & $83588^{*}$ & 89 \\
\hline UFRGS 18 & 2419 & $\mathrm{~b}$ & $0,71^{\mathrm{ns}}$ & $1065363^{*}$ & 57 & 512 & $\mathrm{~d}$ & $0,25^{*}$ & $90127^{*}$ & 87 \\
\hline UFRGS 19 & 2888 & $\mathrm{~b}$ & $0,84^{\mathrm{ns}}$ & $254684^{*}$ & 81 & 900 & $\mathrm{c}$ & $0,82^{\mathrm{ns}}$ & $476713^{*}$ & 64 \\
\hline URS 20 & 3399 & $\mathrm{a}$ & $0,77^{\mathrm{ns}}$ & $349926^{*}$ & 76 & 1268 & $\mathrm{~b}$ & $1,01^{\mathrm{ns}}$ & $164405^{*}$ & 84 \\
\hline URS 21 & 3563 & $\mathrm{a}$ & $1,38 *$ & $434784^{*}$ & 73 & 2256 & $\mathrm{a}$ & $1,57 *$ & $356700^{*}$ & 71 \\
\hline URS 22 & 2740 & $\mathrm{~b}$ & $1,64^{*}$ & $496418^{*}$ & 69 & 980 & $\mathrm{c}$ & $0,50 *$ & $220159^{*}$ & 82 \\
\hline OR 2 & 3635 & $\mathrm{a}$ & $1,40 *$ & $239423^{*}$ & 81 & 1578 & $\mathrm{~b}$ & $1,78^{*}$ & $47820^{*}$ & 90 \\
\hline OR 3 & 3329 & $\mathrm{a}$ & $1,26^{\mathrm{ns}}$ & $128689^{*}$ & 86 & 1055 & $\mathrm{c}$ & $1,66^{*}$ & $81706^{*}$ & 89 \\
\hline OR 4 & 3358 & $\mathrm{a}$ & $1,06^{\mathrm{ns}}$ & $345522 *$ & 79 & 1041 & $\mathrm{c}$ & $1,87^{*}$ & $26779^{*}$ & 91 \\
\hline FAPA 4 & 3548 & $\mathrm{a}$ & $1,25^{\mathrm{ns}}$ & $129120^{*}$ & 85 & 1711 & $\mathrm{~b}$ & $1,81^{*}$ & $207523^{*}$ & 82 \\
\hline IAC 7 & 2748 & $\mathrm{~b}$ & $1,18^{\mathrm{ns}}$ & $103188^{*}$ & 86 & 1011 & $\mathrm{c}$ & $0,80^{\mathrm{ns}}$ & $76475^{*}$ & 89 \\
\hline Médias & 3027 & & - & - & - & 1065 & - & - & - & - \\
\hline C.V. & 14 & & - & - & - & 25 & - & - & - & - \\
\hline
\end{tabular}

${ }^{1}$ Médias não seguidas de mesma letra diferiram significativamente entre si, pelo teste de Scott e Knott em nível de 5\% de probabilidade erro. $* 5 \%$ de probabilidade, pelo teste $t$.

respectivamente); entretanto, a mesma resposta de comportamento não foi observada para o cultivar URS 22 , que apresentou $b_{1}$ maior $(1,64)$ e menor $(0,50)$ que 1 (significativo em $5 \%$ ), nas condições de ambientes favoráveis e desfavoráveis, respectivamente. Ainda pode ser observado que os cultivares UPF 15, UPF 19 e UFRGS 15 apresentaram $b_{1}$ significativo menor que 1 , tanto na condição de ambientes favoráveis $(0,53,0,24$ e 0,53 , respectivamente $)$, quanto na condição de ambientes desfavoráveis $(0,21,0,41$ e 0,11 , respectivamente); assim, estes genótipos apresentam adaptabilidade a ambientes desfavoráveis e não respondem à melhoria de ambiente.

Em presença de aplicação de fungicida (Tabela 3), os desvios das regressões foram significativos para todos os genótipos avaliados, com exceção apenas para o cultivar UFRGS 14, que evidenciou estabilidade de comportamento na condição de ambientes desfavoráveis. Da mesma forma, sem a aplicação de fungicida (Tabela 4), apenas os cultivares UPFA 20 (ambientes favoráveis) e UFRGS 16 (ambientes desfavoráveis), evidenciaram estabilidade de comportamento. Os altos valores da estimativa de $\mathrm{R}^{2}$, evidenciados para a grande maioria dos genótipos avaliados revela o ajuste do modelo adotado em explicar a variação dos dados. Entretanto, nenhum cultivar apresentou biótipo ideal de constituição genética conforme preconizado pelo modelo de EBERHART \& RUSSELL (1966). As significâncias dos desvios podem ser indicativas de instabilidade de rendimento nos ambientes favoráveis ou menos favoráveis, ou de inadequação do modelo estatístico utilizado, ou ainda, de falha do índice de ambiente na representação da produtividade do ambiente. Essa falha pode decorrer de diferenças de comportamento dos cultivares em relação a características específicas do ambiente (KNIGHT, 1970).

Ciência Rural, v.35, n.2, mar-abr, 2005. 


\section{CONCLUSÕES}

O uso de técnicas de aferição da interação genótipos $\mathrm{x}$ ambientes pode auxiliar com qualidade a indicação de genótipos mais responsivos às condições específicas de ambientes (favoráveis e desfavoráveis), sob condições de presença ou ausência de fungicida. Também a estratificação do ambiente de cultivo é um fator decisivo para a obtenção de estimativas dos parâmetros de adaptabilidade e estabilidade mais consistentes, justificando, desta forma, o emprego de estimativas em ambientes estratificados. Dentre as constituições genéticas avaliadas, nenhuma revela biótipo ideal, como preconizado pelo modelo adotado.

\section{REFERÊNCIAS BIBLIOGRÁFICAS}

ALLARD, R.W.; BRADSHAW, A.D. Implications of genotypeenvironment interaction in applied plant breeding. Crop Science, Madison, v.4, p.503-508, 1964.

BENIN, G. et al. Implicações do ambiente sobre o rendimento de grãos em aveia e suas influências sobre estimativas de parâmetros genéticos. Revista Brasileira de Agrociência, Pelotas, v.9, n.3, p.207-214, 2003.

CRUZ, C.D. Programa genes: aplicativo computacional em genética e estatística. Viçosa : UFV, 2001. 648p.

CRUZ, C.D.; REGAZZI, A.J. Modelos biométricos aplicados ao melhoramento genético. Viçosa : UFV, 1997. 390p.
EBERHART, S.A.; RUSSELL, W.A. Stability parameters for comparing varieties. Crop Science, Madison, v.6, n. 1, p.36-40, 1966.

FEDERIZZI, L.C. et al. Estabilidade do rendimento de grãos em aveia: efeito do uso de fungicida. Pesquisa Agropecuária Brasileira, Brasília, v.28, n.4, p.465-472, 1993.

FREY, K.J. Adaptation reaction of oat strains selected under stress and non-stress environmental conditions. Crop Science, Madison, v.4, p.55-58, 1964.

HOLLAND, J.B. et al. Recurrent selection in oat for adaptation to diverse environments. Euphytica, Wageningen, v.113, p.195205, 2000.

KNIGHT, R. The measurement and interpretation of genotype environment interactions. Euphytica, Wageningen, v.19, p.225235,1970 .

LORENCETTI, C. et al. Implicações do uso de fungicida nos parâmetros de adaptabilidade e estabilidade de rendimento de grãos em cultivares de aveia branca. Ciência Rural, Santa Maria, v.34, n.4, p.693-700, 2004.

MARCHIORO, V.S. et al. Dissimilaridade genética entre genótipos de aveia. Ciência Agrotécnica, Lavras, v.27, n.2, p.285-294, 2003

OLIVEIRA, A.C. Comparação de alguns métodos de determinação da estabilidade em plantas cultivadas. 1976. 64f. Dissertação (Mestrado em Ciências Agrárias) - Universidade de Brasília.

RHOLF, F. Numerical taxonomy and multivariate analysis system: version 2.10. New York: [s.n.], 2000. 38p. 